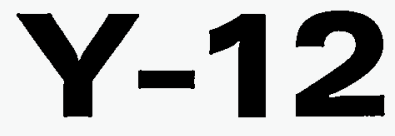

OAK RIDGE Y-12 PLANT

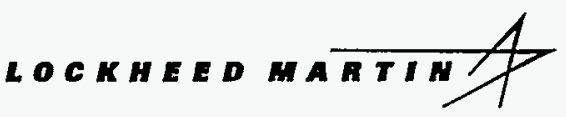

\section{DETERMINATION OF MEASUREMENT UNCERTAINTY ON COORDINATE MEASURING MACHINES BY MEASUREMENT DECOMPOSITION AND UTILIZATION OF CANONICAL ARTIFACTS}
August 1996
EEC 201996
Bruce Cox

$$
05 \pi
$$

Oak Ridge Centers for Manufacturing Technology U.S. Department of Energy Facilities Oak Ridge, Tennessee

Prepared by the Oak Ridge Y-12 Plant Oak Ridge, Tennessee 37831-8091

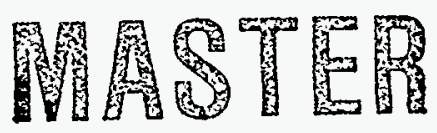

Managed by

Lockheed Martin Energy Systems, Inc. for the U.S. Department of Energy under contract DE-AC05-84OR21400

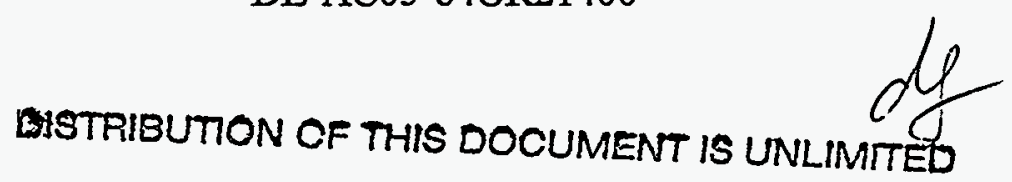




\section{DISCLAIMER}

This report was prepared as an account of work sponsored by an agency of the United States Government. Neither the United States Government nor any agency thereof, nor any of their employees, makes any warranty, express or implied, or assumes any legal liability or responsibility for the accuracy, completeness, or usefulness of any information, apparatus, product, or process disclosed, or represents that its use would not infringe privately owned rights. Reference herein to any specific commercial product, process, or service by trade name, trademark, manufacturer, or otherwise, does not necessarily constitute or imply its endorsement, recommendation, or favoring by the United States Government or any agency thereof. The views and opinions of authors expressed herein do not necessarily state or reflect those of the United States Government or any agency thereof. 


\title{
Determination of Measurement Uncertainty on Coordinate Measurement Machines by Measurement Decomposition and Utilization of Canonical Artifacts
}

\author{
August 1996
}

Bill Rasnick, Bruce Cox, and Mike Sherrill

Oak Ridge Metrology Center

Oak Ridge Centers for Manufacturing Technology

U.S. Department of Energy Facilities

Oak Ridge, Tennessee

\author{
Prepared by \\ the Oak Ridge Y-12 Plant \\ Oak Ridge, Tennessee 37831-8091 \\ Managed by \\ Lockheed Martin Energy Systems, Inc. \\ for the \\ U.S. Department of Energy \\ under contract \\ DE-AC05-84OR21400
}

DISCLAIMER

This report was prepared as an account of work sponsored by an agency of the United States Government. Neither the United States Govemment nor any agency thereof, nor any of their employees, makes any warranty, express or implied, or assumes any legal liability or responsibility for the accuracy, completeness, or usefulness of any information, apparatus, product, or process disclosed, or represents that Its use would not infringe privately owned rights. Reference herein to any specific commercial product, process, or service by trade name, trademark, manufacturer, or otherwise, does not necessarily constitute or imply its endorsement, recommendation, or favoring by the United States Govemment or any agency thereof. The views and opinions of authors expressed herein do not necessarily state or reflect those of the United States Government or any agency thereof. 


\section{DISCLAIMER}

Portions of this document may be illegible in electronic image products. Images are produced from the best available original document. 


\section{Determination of Measurement Uncertainty on Coordinate Measurement Machines by Measurement Decomposition and Utilization of Canonical Artifacts}

The requirement for primary-level calibration of complex forms-e.g., gear profiles-has led to development of a method for quantifying the measurement uncertainty on the artifact being calibrated that does not rely on a transfer comparison. This method, developed jointly by National Institute of Standards and Technology (NIST) and Oak Ridge Metrology Center (ORMC) personnel, consists of breaking down the measurement method into simpler components and quantifying these components using generally accepted artifacts with low uncertainties (gage blocks, ring gages, spheres, etc.). Once quantified, these components are added vectorially according to NIST Technical Note 1297, 1994 Edition. ${ }^{1}$ Verification of this method can be accomplished by intercomparisons with other methods and laboratories.

\section{INTRODUCTION}

Computer-controlled coordinate measuring machines offer exciting new capabilities not only for industrial quality control tasks but also for calibration of artifacts of complex form. The complexity of most of these measurement tasks creates difficulties in quantifying uncertainties associated with such measurements. There is also no standard for determination of uncertainty; however, there are at least five prevalent approaches used in industry. These are as follows:

1. Global approach (applicable to any measurement within a tested machine volume). Some people use ANSI/ASME B89.1.12M-1990 ${ }^{2}$ or similar performance tests to form a basis for uncertainty estimates. Although this approach can be considered all-encompassing, it can produce uncertainty estimates higher than would be realized by a more specific detailed approach.

2. Virtual coordinate measuring machine (CMM). This method can be quite complex. It requires a detailed model of all the machine and probing errors. Once this model is created, the predicted machine errors can be combined appropriately with the artifact geometry to predict the measurement errors for specific measurement tasks. The uncertainty then becomes dependent upon the uncertainty of the error mapping process and the stability of the error map. This method is under development by a number of research groups, but no commercial product is available yet.

3. Comparator method. Using the CMM as a comparator involves measuring a master artifact and a test artifact one after the other in the same position on the CMM. Comparison measurements can provide very low uncertainties, essentially down to the repeatability of the CMM. Because a calibrated artifact nearly identical to the workpiece is required for each and every different workpiece type, this method, while yielding the lowest uncertainty, can negate the universality of the CMM. 
4. Surrogate artifact. Some measurement tasks can be approximated by measurements on a spatial arrangement of canonical (simple geometry, low uncertainty) artifacts. If the canonical artifacts and their relationship to each other can be measured by low uncertainty methods, then the resulting artifact can become an uncertainty-determining artifact. This method is only slightly more general than the comparator method, and any significant departure from the workpiece size and/or shape would dictate the creation of a new surrogate.

5. Decomposition. Breaking down the complex measurement process into its basic components can offer a more general solution to measurement uncertainty determinations. Each of these basic processes can, in turn, be characterized by using canonical artifacts. Well-thought-out consideration of all sources of uncertainty is needed to ensure that all the building blocks are included.

This paper describes the general concept of measurement decomposition and provides specific examples of its application as related to two metrology projects encountered at ORMCcalibration of a ball bar and an involute profile master.

\section{CONCEPT}

Conceptually decomposing the task into its more fundamental subtasks such as alignment, translation, and form measurement can initially seem to be a daunting endeavor. However, most CMM programmers compose their routines from various simpler tasks as needed, so this type of decomposition can be handled fairly well by one competent in that art.

Decomposition must also take into consideration measuring machine geometry effects. Following are step-by-step guidelines for the decomposition process.

1. Analyze the measuring task: break down the total task into elemental tasks.

2. Model the effect of error in each elemental task on the final measurement(s).

3. Trace the plausible causes of each of these errors back to a measuring system error.

4. Devise tests to measure each individual machine error or the resultant effect on the individual element task.

(a) Approximate as closely as possible the actual elemental measurement.

(b) Use artifacts with very low uncertainty (canonical artifacts), such as gage blocks (length and angle); spheres; optical flats; and ring gages.

5. Calculate the cumulative effect of each of these errors using the above model.

(a) Propagate the uncertainty of each subtask down to the effect on the final measurement.

(b) Assume a distribution (rectangular, triangular, or Gaussian) for the error effects. 
(c) Calculate the standard deviation of the error effects and combine these effects in quadrature including the uncertainty of the canonical artifact(s). (Refer to NIST Technical Note 1297. ${ }^{1}$ )

\section{EXAMPLES}

Two examples of the decomposition process are described below. The first is the calibration of the distance between the center of the precision spheres of a ball bar. The second is a gear profile master which requires calibration of the portion of the artifact that simulates the gear tooth profile.

\section{Ball Bar Calibration}

A ball bar can best be described as a precision dumbbell-two spheres attached to the ends of a metal cylinder (Fig. 1). The measurement of interest is the distance between the centers of the two spheres. For the past decade the comparison of measured center-to-center distances for multiple positions and/or orientations of the ball bar in the CMM measurement volume has been an important characteristic for evaluating CMM performance.

Y-96T-662pt

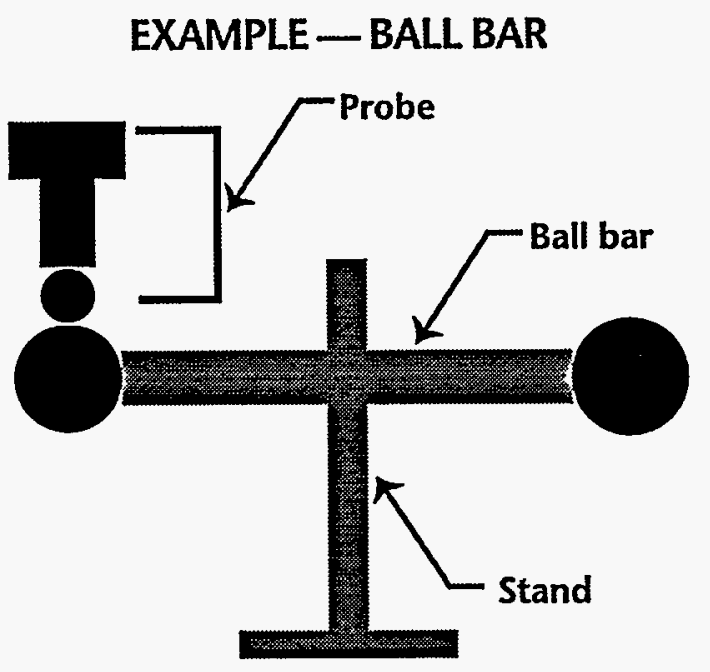

Fig. 1. Typical ball bar and stand for measuring ball bars with both ends free using active probes. 
When a request for ball bar calibration was submitted to ORMC, the measurement uncertainty was determined by using task decomposition methodology. The measurement instrument chosen for the calibration was a Moore M-60 UMM (Fig. 2). This machine has a stated expanded uncertainty in its $x$-axis (2 sigma) of $\pm(0.3+0.4 \mathrm{~L}) \mu \mathrm{m}$, where $L=$ length in meters.

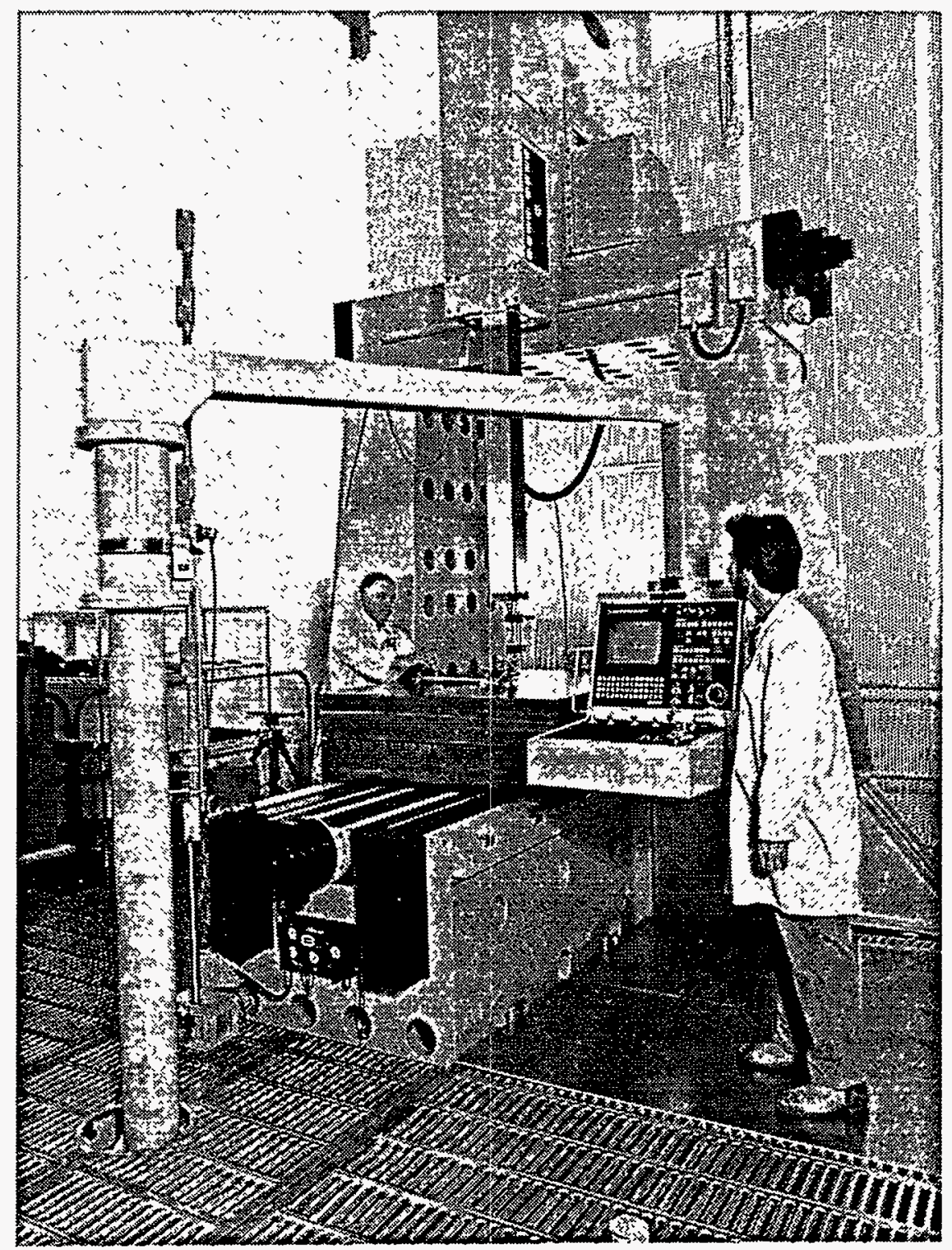

Fig. 2. Moore M-60 UMM coordinate measuring machine. 
Details of the factors and components that were included in determination of the M-60 uncertainty are given in Y-12 Technical Report Y/AMT-145. ${ }^{3}$ Table 1 shows a compilation of the uncertainty estimates (in a one standard deviation form) from the document.

Table 1. Error source uncertainties for Moore M-60 UMM

\begin{tabular}{lc}
\hline \multicolumn{1}{c}{ Factor } & Uncertainty estimate \\
\hline \multicolumn{2}{c}{ Length-independent uncertainty $(\mu \mathrm{m})$} \\
Machine positioning: geometry & 0.051 \\
Length measuring nonrepeatability & 0.102 \\
Probe tip calibration & 0.054 \\
Artifact quality & 0.076 \\
Total length-independent uncertainty & 0.15 \\
\multicolumn{2}{c}{ Length-dependent uncertainty $(\mathrm{ppm})$} \\
Machine positioning: scale & 0.152 \\
Artifact temperature & 0.098 \\
Laser alignment & 0.04 \\
Total length-dependent uncertainty & 0.18 \\
\hline
\end{tabular}

The total task was decomposed into two simpler tasks: a one-dimensional length measurement and two determinations of the center point of a sphere. The next step in the process was to determine the influence of any errors in these two measurements on the final results. Obviously, any error in the 1-D component will affect the final distance between centers by a 1 to 1 ratio. An error in determination of sphere center must be resolved along the bar axis.

Two reference artifacts were chosen for the ball bar. A sphere is by definition a canonical ball bar. Its length is known to be zero. A precision-calibrated sphere of approximately the same size as the ball bar spheres was probed with the spatial point distribution used on the actual ball bar. This pattern was mirrored and the sphere probed again. Next, a well-characterized, lowuncertainty, long gage block was measured in approximately the same direction and at the same location as the ball bar. The gage block was used to confirm the previously determined 1-D uncertainty as referenced in Y-12 Technical Report Y/AMT-145. ${ }^{3}$

Since the ball bar artifact is of a significantly different shape than the typical 1-D length artifacts calibrated on the M-60, different components and their estimates are required for lengthindependent ball bar calibration uncertainties.

The first difference relates to the measurement nonrepeatability. For ball bar estimation an 18-point measurement pattern and a mirror image pattern are made on the standard ball; then, a least squares sphere fit routine is used to determine the center of the ball by each pattern. The variability found in the differences between center points during repeated checks of the ball using 
mirror image patterns permit an estimate of the uncertainty in finding center points along the $x$-axis by this technique. This method differs greatly from that of the small (5-point) probing pattern on each end of an end standard, eliminating the need to include an uncertainty component for the probe tip diameter. Another difference is that the estimated artifact quality of a standard ball is routinely not the same as the estimate included for the M-60 end standard in Table 1 .

Regarding the length-dependent uncertainty estimate, gage blocks are end standards, so the reported M-60 length-dependent uncertainty estimates should be appropriate for this portion of the evaluation. Repeated runs verified this assumption.

The methods in NIST Technical Note $1297^{1}$ were used to determine estimates of the uncertainty components. In cases where appropriate, Gaussian distribution standard deviations were used as estimates. When distributions were not known or could not be assumed, the rectangular or uniform distribution approach, in which range data are used to estimate standard deviations, was used to determine the estimate.

Finally, when evaluating the results of repeated runs on standards, a check for systematic errors (biases) is important. For example, did the mirror image patterns give center-point differences that are consistently larger or smaller than zero by about the same amount? They did not for this artifact, nor was a bias noted for the gage block measurements.

NIST Technical Note $1297^{1}$ assumes that all such biases are corrected or removed, so that variation is represented by the standard deviation only. If this is not practical, some method must be devised to accommodate the bias in the overall uncertainty statement. Use of the rectangular distribution approach can sometimes be used to accomplish this goal.

Table 2 contains the estimates (in standard deviation form) for each major component of the 12-in. ball bar checked on the M-60 at Y-12.

Table 2. Error sources and values for Moore M-60 UMM modified for ball bar

\begin{tabular}{lc}
\hline \multicolumn{1}{c}{ Factor } & Uncertainty estimate \\
\hline \multicolumn{1}{c}{ Length-independent uncertainty $(1$ sigma $)$} \\
Machine positioning: geometry & $0.051 \mu \mathrm{m}$ \\
Length measuring nonrepeatability & $0.049 \mu \mathrm{m}$ \\
Artifact quality & $0.029 \mu \mathrm{m}$ \\
Total length-independent uncertainty & $0.076 \mu \mathrm{m}$ \\
\multicolumn{2}{c}{ Length-dependent uncertainty } \\
$(2$ sigma $)$ \\
Length-dependent factor & $0.4 \mathrm{ppm}$ \\
Total length-dependent uncertainty & $0.4 \times 0.0254=0.122 \mu \mathrm{m}$ \\
Total uncertainty (2 sigma) & $2(0.076)+0.122=0.3 \mu \mathrm{m}$ \\
\hline
\end{tabular}




\section{Gear Profile Master Artifact}

As a partner with NIST, American Gear Manufacturers Association, Penn State, and ASME, ORMC has been active in establishing calibration services on certain gear element artifacts, one of which is the gear profile or involute master.

Uncertainty estimation of profile measurements of an involute artifact proved to be a complex and challenging task.

A simple description of this artifact would be a gear with half a tooth mounted on a shaft with/without mounting centers (Fig. 3). Artifacts such as these are used in various quality control functions in the gear manufacturing industry, the most prominent being to monitor and/or adjust the calibration of both manual and computer controlled gear measurement machines.

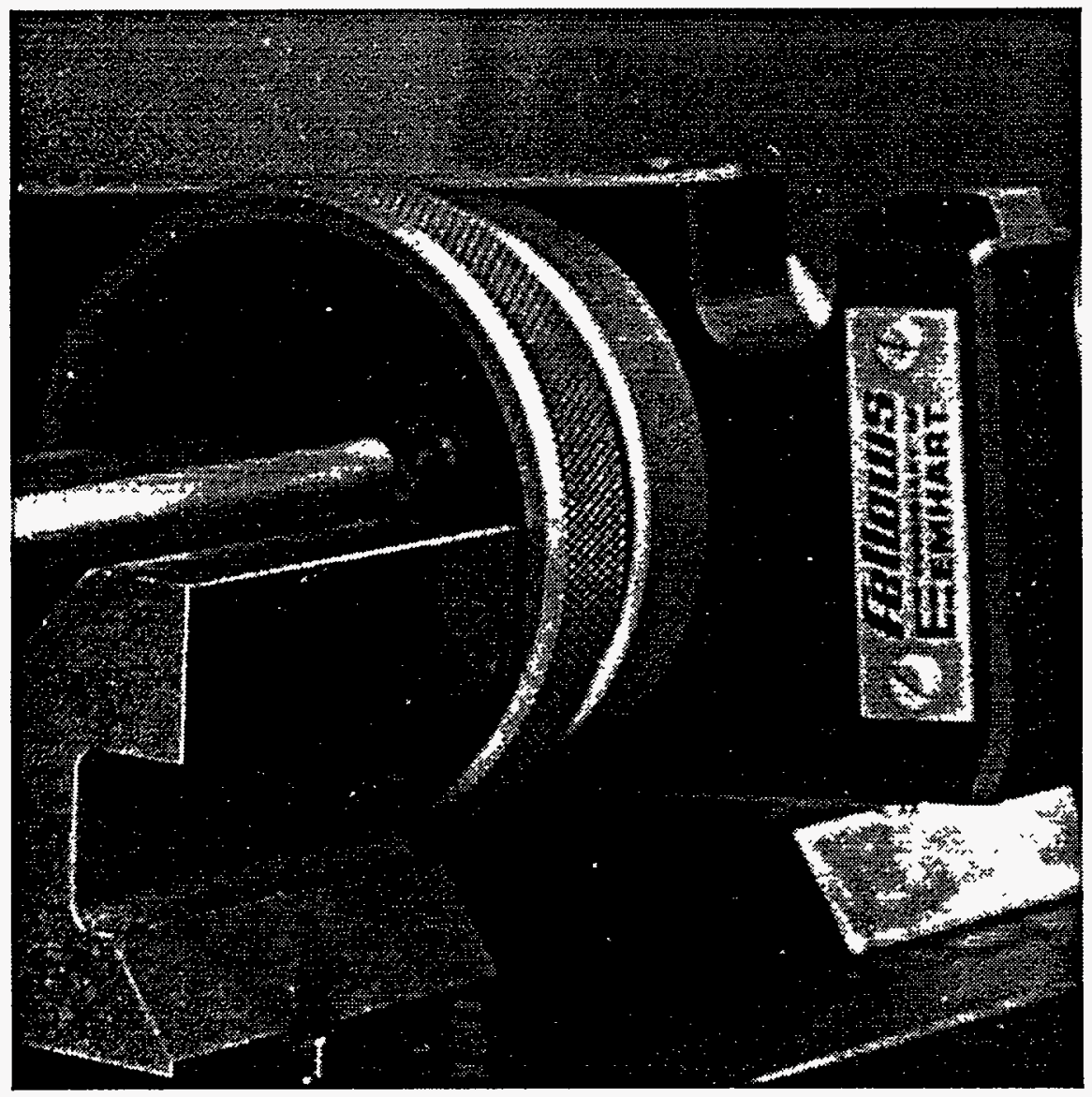

Fig. 3. Fellows 4.5-in. involute profile artifact.

The measurement task starts with measurement of shaft datum features and calculating the centers of these features. An axis is constructed between these centers. This axis is the reference axis for the gear profile. By definition, the first point of the gear profile is also a reference. Once a reference system is established, the profile can be measured. 
The instrument chosen for this task was a Leitz $866 \mathrm{PMM}$ high-precision measuring machine with a 3-D analog measuring head (Fig. 4).

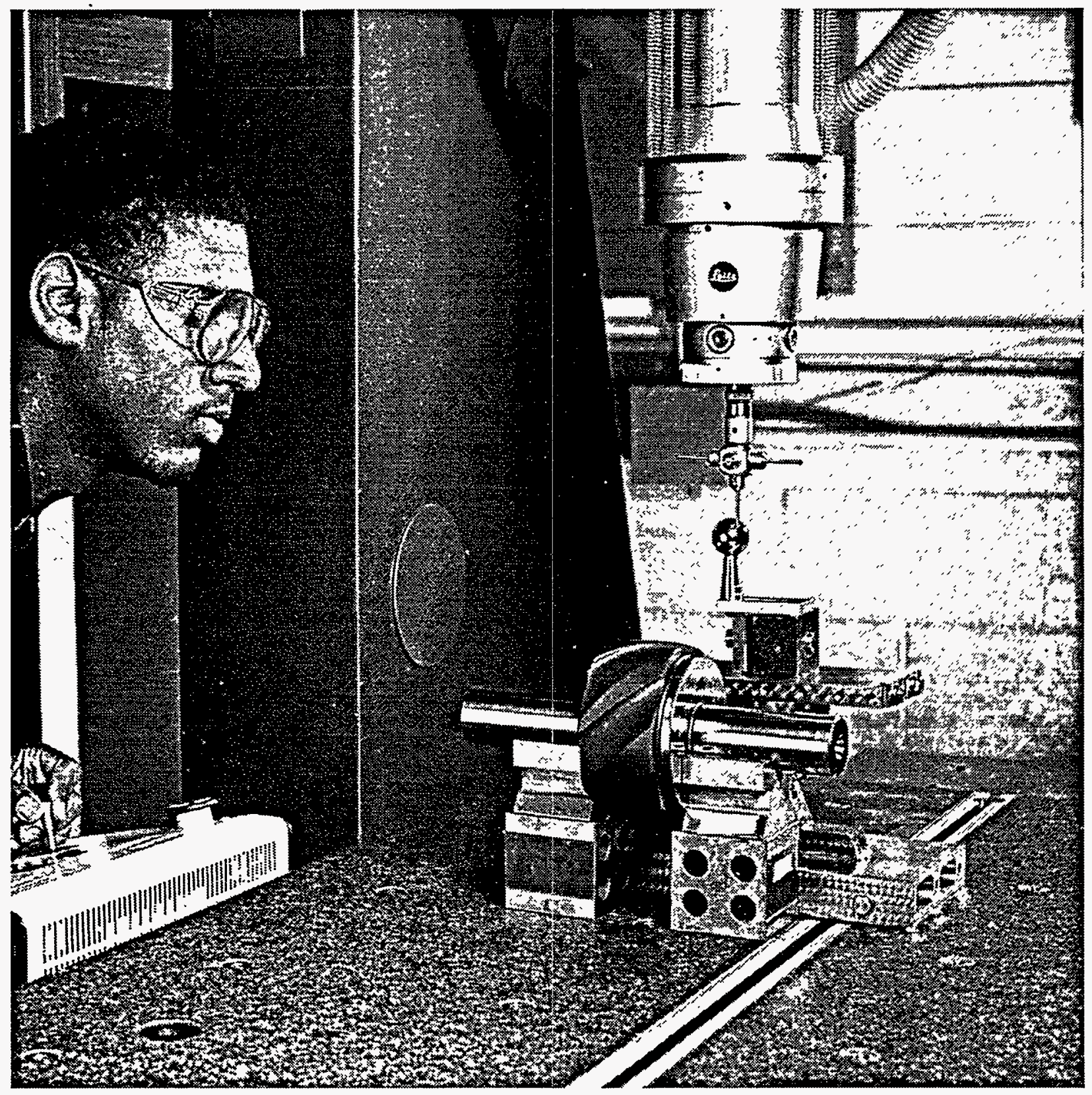

Fig. 4. Leitz 866 PMM coordinate measuring machine.

Task decomposition was as follows:

1. measuring the centers of two circles and calculating a line between them,

2. translating a certain distance away from this line, and

3. measuring a series of points along the involute profile and determining the normal deviation of each point from the theoretical. 
The corresponding error effect for each element was modeled and is listed below:

1. Any error in determining the centers of the reference or datum surfaces will naturally result in an error in locating the reference axis. This error can have a varying influence upon the profile results depending upon the magnitude and the direction of the misalignment (see Fig. 5). Software routines that compute the effect of given misalignments were developed and verified by comparison with an independently developed CAD model. Appendix A contains results of the CAD model.

Y-96T-651Bpt

\section{EXAMPLE - GEAR PROFILE ARTIFACT}

Shift center " $R$ " radius at " $X$ " angle then rotate about new orgin until no deviation at 6 degrees of roll on involute curve

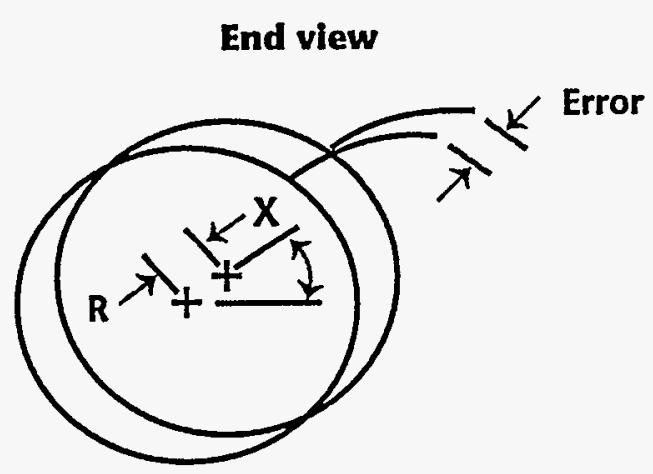

Side view

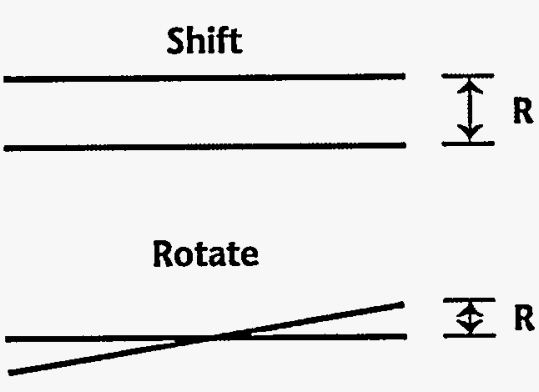

Shift and rotate

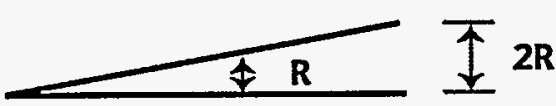

Fig. 5. Error on involute curve due to misalignment.

2. The profile error resulting from the translation error is variable along the surface of the profile master. Near the start of the master the surface normal vectors are nearly perpendicular to the translation direction. Near the end of the profile the surface normal angles are approximately $60^{\circ}$ or less. Using the dot product between the translation and the surface normal vector provided the resulting profile error.

3. The most influential error is obviously any CMM error in measuring the profile, having a direct 1 to 1 effect.

Likely measuring system errors that would cause the above errors are as follows:

1. Probe registration or calibration errors that produce mislocations of the relative positions of each probe with respect to the others could produce an error in the alignment surface location. 
2. Since the master is oriented on the CMM with the reference axis parallel to the CMM $y$-axis and the initial radial line parallel to the CMM $x$-axis, any linear error in the $x$ direction at the same approximate $z$ height would produce the translational error.

3. The probe tip out of roundness, probe size errors, and probe deflection compensation errors, in addition to machine positioning errors, will overlay directly onto the profile measurements.

For each of these error models the following tests were devised:

1. A circular section of a calibrated sphere was measured twice, once with each probe tip that measures the datum surfaces.

2. A gage block of the approximate radius from the center axis to the profile was measured in a line parallel to the radial line from the axis to the initial profile point.

3. The profile of a circular section of the calibrated sphere was measured with the section being in the same approximate plane of the profile and the surface normal vectors on the sphere covering the range of surface normal vectors on the profile master (see Figs. 6-8).

Not all sources of uncertainty can be determined by tests on canonical artifacts. Although beyond the scope of this paper, these sources and their respective tests are listed for the sake of completeness.

1. Any $x$ motion in the $y$-axis could produce an apparent error in the center axis determination. This potential source of error was tested

EXAMPLE — GEAR PROFILE ARTIFACT

Involute artifact measurement decomposition

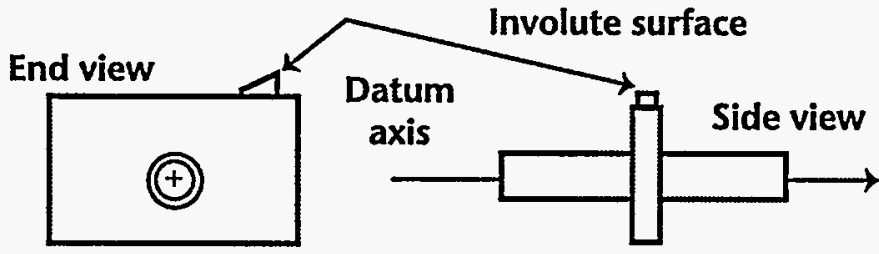

Alignment test $\mathrm{A}$,

Probe Registration

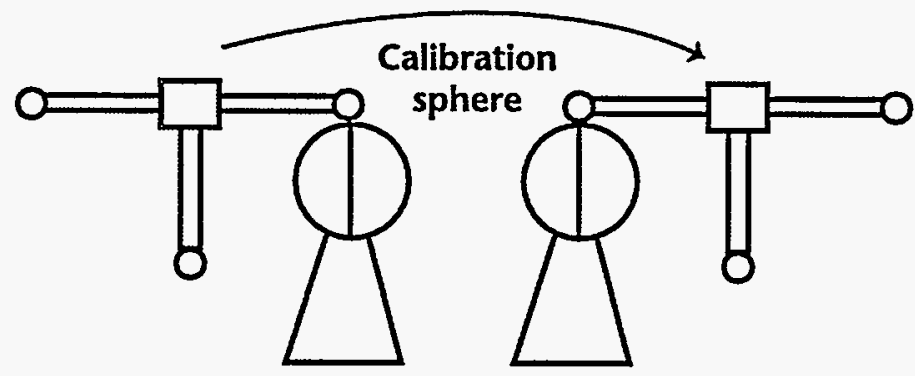

Fig. 6. Involute artifact measurement decomposition: alignment test $\mathrm{A}$. with a reversal method whereby the involute artifact or a surrogate was measured in two opposite orientations (rotated $180^{\circ}$ around the $z$-axis). The effect of this error was then fed into the appropriate error calculation. 


\section{EXAMPLE - GEAR PROFILE ARTIFACT}

Alignment test $B$,

Reversal

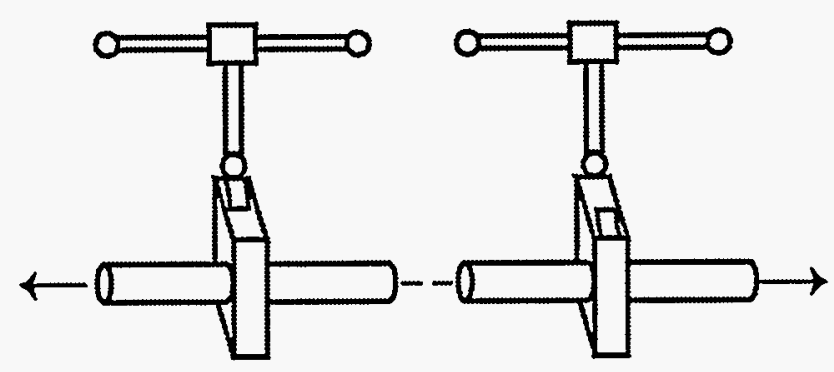

Translation Test

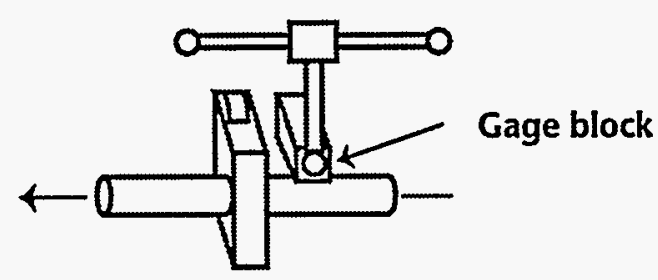

Fig. 7. Involute artifact measurement decomposition: alignment test $B$ and translation test.

Y-96T-651jpt

\section{EXAMPLE - GEAR PROFILE ARTIFACT}

Profile test

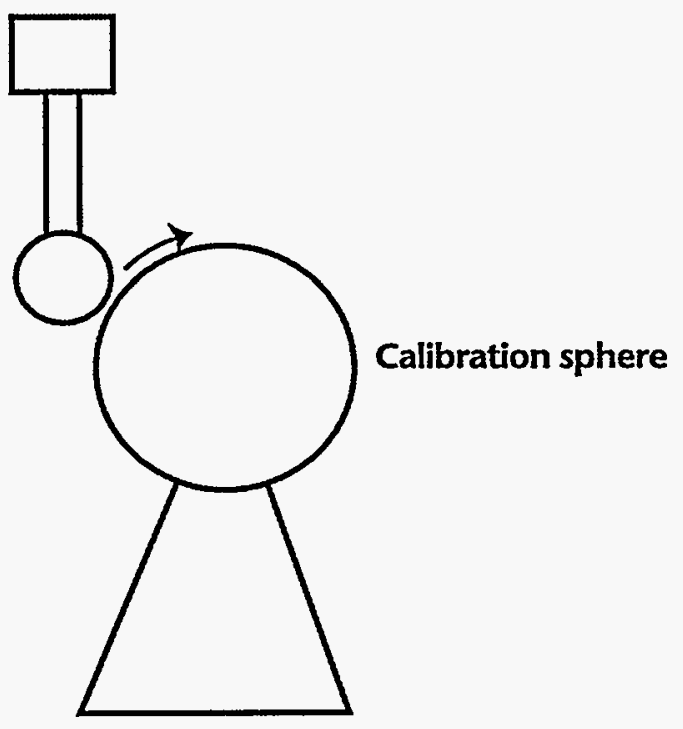

Fig. 8. Involute artifact measurement decomposition: profile test. 
2. Repeatability of measurements is always a primary source of uncertainty. Various causes such as temperature, vibration, and any undetermined factors, while not easy to single out, can be tested for total effect. By running repeated measurements over an extended period $(24-48 \mathrm{~h})$, this variation can be established and statistically characterized.

3. The quality of the artifact surfaces themselves can influence the variation between measurements. Not only the feature of interest (in this case the involute profile) but also the datum surfaces must be of sufficient form variation and surface quality. In the case being examined, the roundness of the datum axis features proved to be critical. Consequently, the roundness had to be characterized before further calibration work could continue.

4. Although temperature is closely controlled and monitored, there remains an uncertainty in the temperature measurement and the assumed value for the coefficient of thermal. expansion (CTE). These uncertainties were conservatively assumed to be $0.1^{\circ} \mathrm{C}$ and $1 \mathrm{ppm} /{ }^{\circ} \mathrm{C}$, respectively. An estimate of these effects on the profile uncertainty was calculated by expanding and contracting the radial component of the profile coordinates to determine the error limits produced by the temperature and CTE effects.

As in the previous example, a rectangular instead of Gaussian distribution was assumed, and the standard deviation was calculated from the range data, per suggestions of NIST Technical Note $1297^{1}$. Two exceptions were the cases for the gage block measurement and the repeatability of measurements, where a Gaussian distribution was appropriate. In all, there were seven components of uncertainty that were calculated as standard deviations and root-sum-squared to provide the overall standard deviation of uncertainty. Multiplying by 2 gave a final total 2 sigma (95\%) uncertainty of $\pm 0.9 \mu \mathrm{m}$.

In order to verify the uncertainty estimate, three independent measurements were made for intercomparison. A surrogate artifact was available from a previous experiment. This artifact is a spatial arrangement of three precision spheres that closely simulates the basic elements of a gear profile master (Fig. 9). Previous measurements provided an informal 2-sigma estimated uncertainty of $\pm 0.2 \mu \mathrm{m}$ on the spherical section that approximates the gear profile. CMM profile measurements on this artifact and subsequent calculations resulted in a 2-sigma uncertainty of $\pm 0.8 \mu \mathrm{m}$.

Measurements on two involute artifacts were also made at NIST. Although NIST equipment is similar, the analysis application software was developed independently, different personnel operate the equipment, and holding fixtures are different. All NIST and Y-12 measurements (on the total mean rise of the profile) were within $0.5 \mu \mathrm{m}$. 


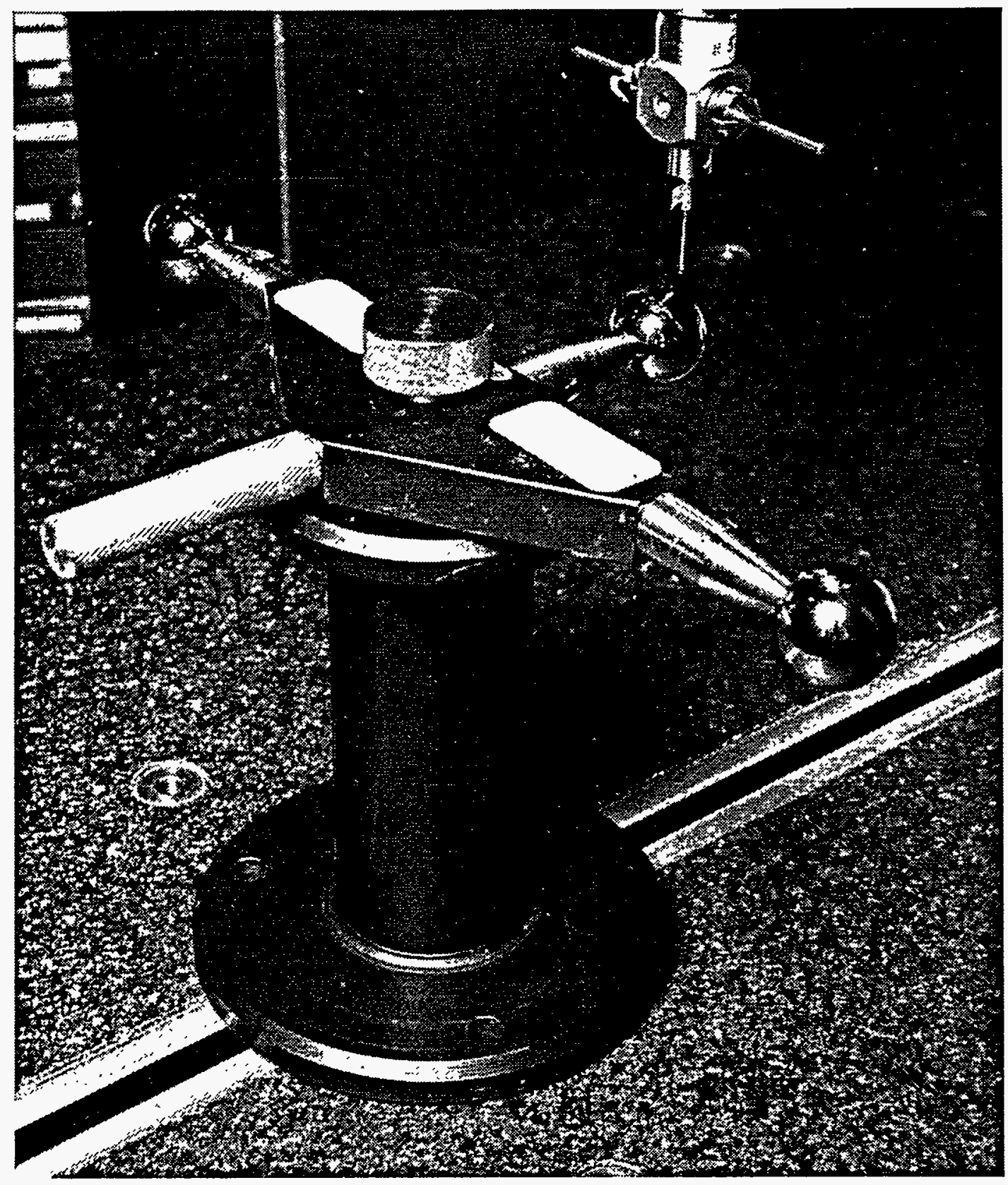

Fig. 9. Three-ball surrogate involute artifact.

Using a third method based on traditional manual metrology methods gave the final affirmation to the uncertainty estimate. This method essentially duplicated the NIST method developed and reported in the 1980s. The NIST method uses a precision rotary stage and linear slide to trace the involute profile (unwound string). Comparison of $0.6 \mu \mathrm{m}$ between the CMM method and the traditional method is shown in Figs. 10 and 11. 


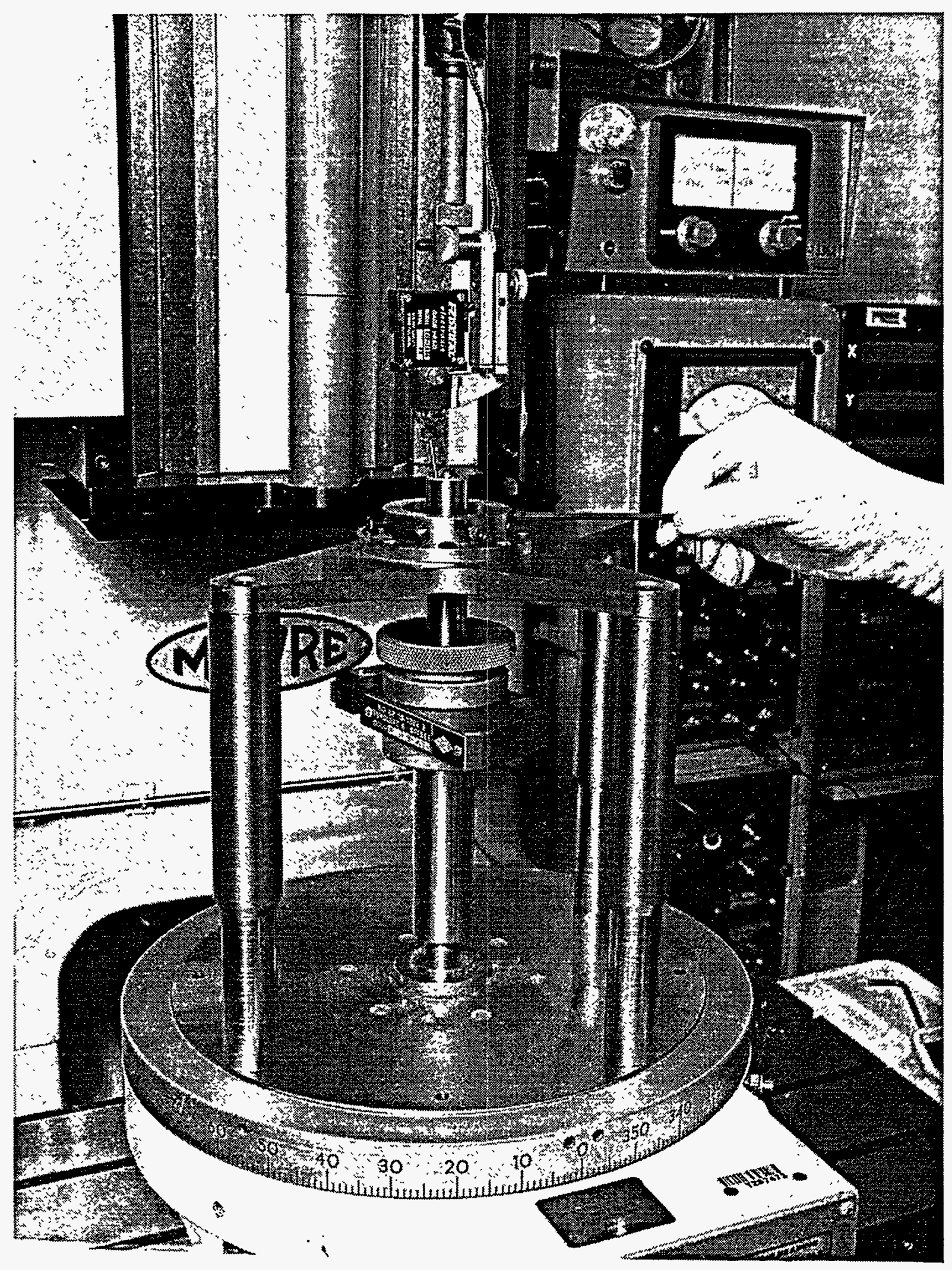

Fig. 10. Traditional manual measurement of involute artifact using a Moore M-18 machine. 


\section{CONFIRMATION}

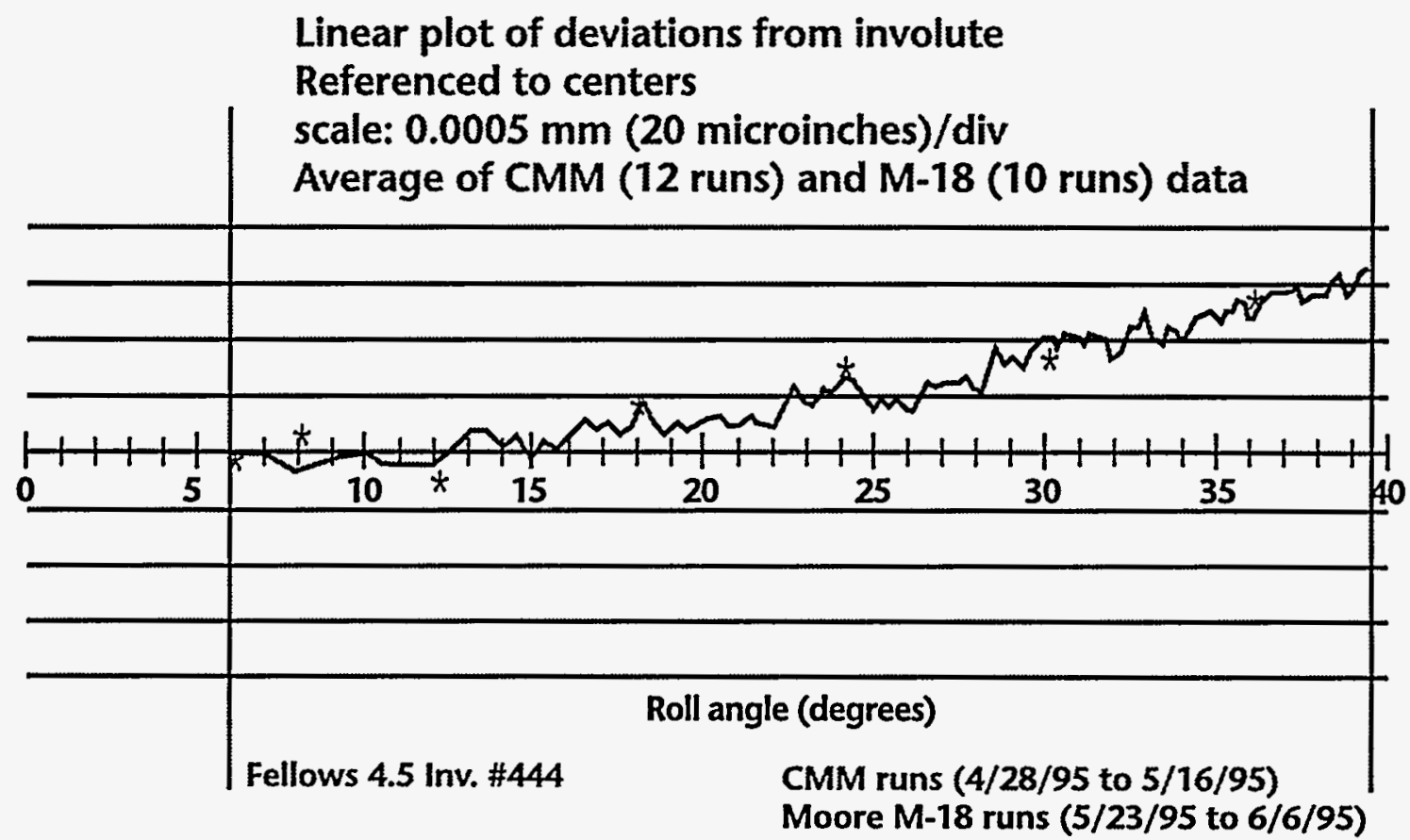

Fig. 11. Comparison between CMM and manual Moore M-18 run for involute artifact.

The consistency of all the intercomparisons indicated that the uncertainty estimate was valid and perhaps a bit conservative. After a review of our data and methods, we published a $0.9 \mu \mathrm{m}$ uncertainty as our calibration service uncertainty.

\section{CONCLUSIONS}

In general, if a calibrated artifact is available at the required level of uncertainty, the time and cost associated with determining measurement uncertainty can be greatly reduced in comparison with the measurement decomposition method.

Where applicable however, measurement task decomposition and use of canonical artifacts are valid and viable means of determining measurement uncertainty and, although tedious and timeconsuming, can be a useful tool in the metrologist's toolbox.

As measurement tasks become more complex, this method can quickly become unwieldy and impractical. However, a combination of simpler artifacts so calibrated can be employed so that their statistically combined uncertainty can be determined. For example, in a complete gear calibration, calibrated gear element artifacts (involute, index, and lead master) could be used to test a gear measurement instrument, providing one component of the total uncertainty. 


\section{ACKNOWLEDGMENTS}

First and foremost, we must acknowledge Dr. Howard Harary of the National Institute of Standards and Technology not only for originating the concept but guiding its implementation. Wayne Randles provided CMM application support. Bill Adkins supervised the testing performed by Danny Roberts and others of the $9201-5 \mathrm{~N}$ inspection area. Nick Zurcher provided peer review and guidance.

\section{REFERENCES}

1. Guidelines for Evaluating and Expressing the Uncertainty of NIST Measurement Results, NIST Technical Note 1297, National Institute of Standards and Technology, Gaithersburg, Md., 1994.

2. Methods for Performance Evaluation of Coordinate Measuring Machines, ANSI/ASME B89.1.12M-1990, ASME, New York, 1990.

3. Calculating Uncertainty of 1-D Measurements on a Coordinate Measuring Machine, Y-12 Technical Report Y/AMT-145, Oak Ridge Y-12 Plant, Oak Ridge, Tenn., 1995. 


\section{APPENDIX A}

A study was conducted on the effect of misalignment on an involute artifact using a CAD system. The artifact modeled was a Fellows 4.5 -in. master, and the CAD system was ANVIL. The model was confirmed by using the Leitz QUINDOS CMM programming language. Figure A.1 shows the effect of a 4- $\mu \mathrm{m}$ shift and rotation of the origin relative to the involute curve. This figure illustrates that the error on the involute curve follows a sinusoidal pattern and that shifting normal to the reference axis of the involute artifact has a much greater effect than rotation normal to the reference axis.

Y-96T-651Cpt

\section{EXAMPLE - GEAR PROFILE ARTIFACT}

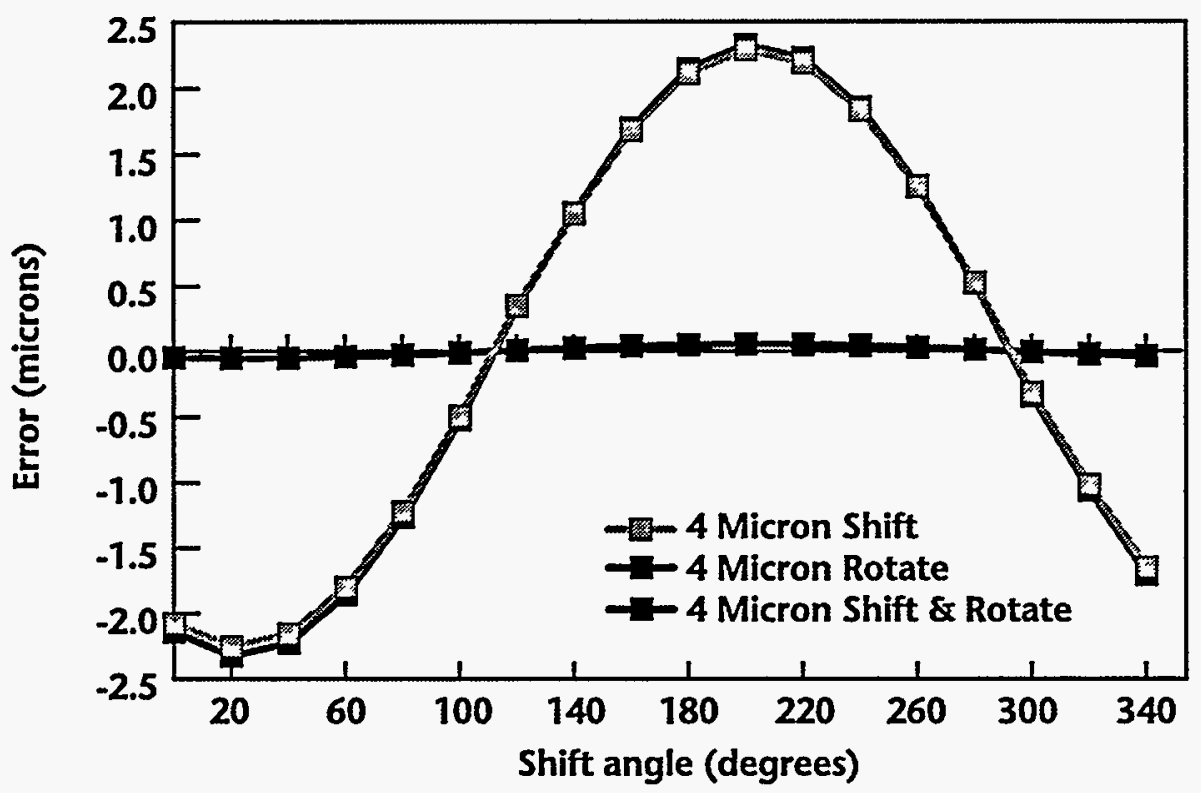

Fig. A.1. Error on involute curve for $4-\mu \mathrm{m}$ shift and rotation of origin.

Figure A.2 shows the effect of different amounts of shift and rotation of the origin in the same direction relative to the involute curve. This figure illustrates that the error on the involute curve is directly proportional to the amount of shift or rotation of the origin.

Figure A.3 shows the maximum error on the involute curve as a function of the amount of shift of the origin. It is clear from this figure that a linear relationship exists for the maximum error on the curve versus the amount of shift or rotation of the origin. 


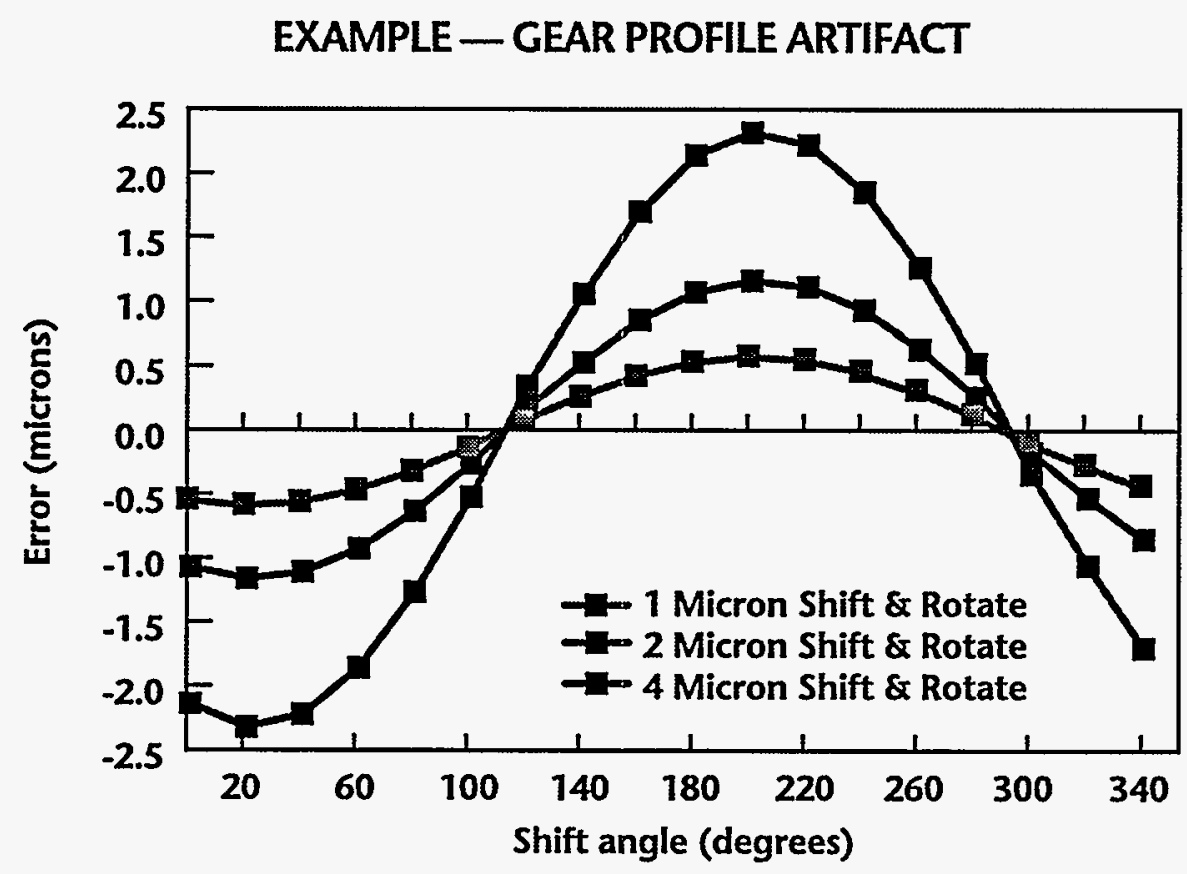

Fig. A.2. Error on involute curve for 1-, 2-, and 4- $\mu \mathrm{m}$ shift and rotation of origin.

Finally, an equation that can be determined for maximum error on an involute curve due to shift or rotation of the origin of the artifact is as follows:

$$
\begin{aligned}
& Y=-a \cos (b X+c) \\
& \text { Maximum Error }=-0.581 R \cos (X-20),
\end{aligned}
$$

where $R=$ radial shift/rotation of origin, $X=$ shift angle in degrees. 


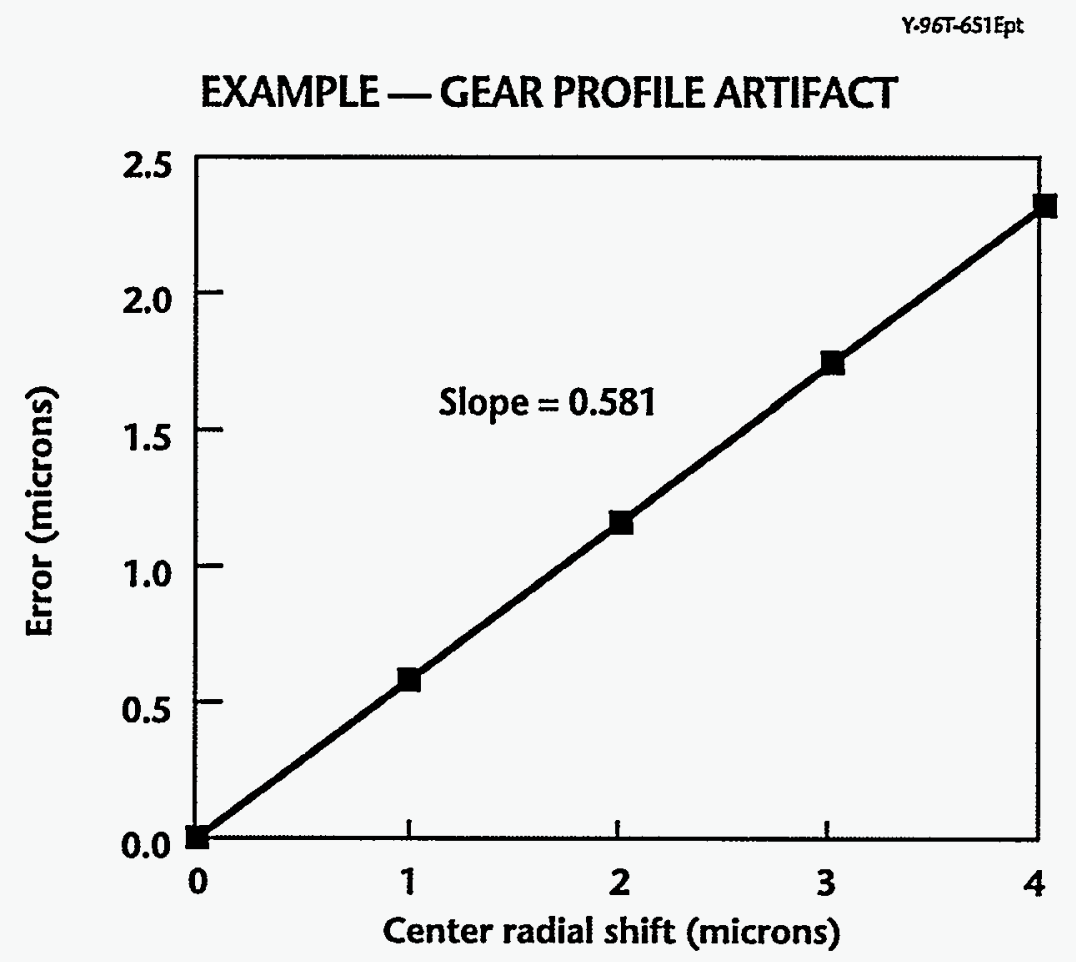

Fig. A.3. Maximum error on involute curve vs center misalignment. 